\title{
Cell-wall Defective Variant of Nocardia rubra
}

\author{
By I. PRASAD AND S. G. BRADLEY \\ Department of Microbiology, Virginia Commonwealth University, \\ Richmond, Virginia 23219 , U.S.A.
}

(Accepted for publication I3 December I97I)

Nocardia rubra strain vac-32 I is a red pigmented actinomycete. It grows very well on peptone + yeast-extract + glucose media. On solid medium it forms compact glazed colonies with distinct radiating hyphae. Microscopic observation of smears made from colonies, reveals many cellular forms: rods, coccoid bodies and mycelial fragments. The cells stain Gram-positive. A white mutant was induced in $N$. rubra by treating the cells with quinacrine at a concentration of $40 \mu \mathrm{g} / \mathrm{ml}$ for $20 \mathrm{~min}$. The white mutant has the same cellular and colonial morphology as the parental $N$. rubra. When the mutant was serially subcultured at $37^{\circ}$, a few red spots appeared on the surface or under the white colonies. Initial attempts to establish subcultures from these red spots gave only white colonies. Subsequently, subcultures were made on peptone + yeast-extract + glucose agar supplemented with sodium chloride or with different antibiotics (Table I). The red variant grew only on media containing penicillin or $\mathrm{NaCl}$. The colonies of the red variant on penicillin- or NaCl-supplemented media grew slowly, were compact and very shiny. The colonies were not raised and formed thin films on the agar. No hyphae were observed microscopically in smears of the red variant, the cells of which were Gram-negative. On this basis it was termed a 'cellwall defective mutant'.

The cell-wall defective mutant $(c w d)$ growing on media supplemented with I500 units penicillin/ml or $0.3 \% \mathrm{NaCl}$ was adapted to grow on unsupplemented peptone + yeast-extract + glucose agar or in broth by serial transfer. For both supplements the growth in broth was greatest when the flasks were incubated at $35^{\circ}$ without agitation. The $c w d$ cells adapted to grow in unsupplemented liquid medium did not fragment, but formed a deeply pigmented

Table I. Effect of drugs on the growth of the cwd variant

Cells of a $c w d$ colony were suspended in hypertonic solution and equal amounts were plated on each solid peptone + yeast-extract + glucose medium supplemented with the drugs listed.

\begin{tabular}{lcc}
\multicolumn{1}{c}{ Addition } & Concentration & Growth \\
No addition & - & - \\
Sodium chloride & $300 \mathrm{mg} / \mathrm{ml}$ & ++++ \\
Penicillin & $1000 \mathrm{units} / \mathrm{ml}$ & ++++ \\
& $1500 \mathrm{units} / \mathrm{ml}$ & ++++ \\
& $2000 \mathrm{units} / \mathrm{ml}$ & +++ \\
Bacitracin & $5 \mu \mathrm{g} / \mathrm{ml}$ & ++ \\
& $10 \mu \mathrm{g} / \mathrm{ml}$ & + \\
& $20 \mu \mathrm{g} / \mathrm{ml}$ & \pm \\
Chloramphenicol & $5 \mu \mathrm{g} / \mathrm{ml}$ & - \\
& $10 \mu \mathrm{g} / \mathrm{ml}$ & \pm \\
Streptomycin & $10 \mu \mathrm{g} / \mathrm{ml}$ & $20 \mu \mathrm{g} / \mathrm{ml}$
\end{tabular}

$-=$ No growth of the $c w d$ variant; + to $++++=$ Io to 40 colonies of the $c w d$ variant. 
orange-red mat either on the surface of the broth or on the bottom of the flask. Because the cells adhered to each other, they could not be dispersed readily for quantitative counts. When an homogenizer was used to disperse the cells, they ruptured. The marked fragility presumably reflected the lack of a rigid cell wall. When the $c w d$ variant reverted to a form with rigid walls, the revertant colonies were white.

Actinophage $\mathrm{MNP}_{4}$ lysed Nocardia rubra strain vac-32I and its derivative white mutant but failed to lyse the $c w d$ mutant. It has been reported that some L-forms of Escherichia coli and Salmonella paratyphi are phage resistant (Landman, 1968) despite the fact that the initial strains were phage sensitive. The properties of the $c w d$ variant might be due to phage activity; accordingly the culture was tested for the presence of temperate phage. Culture filtrate of $c w d$ variant did not result in plaque formation when tested on confluent growth on the wild-type strain vac-321, the white mutant or any of the putative indicator strains tested. Moreover, the $c w d$ variant did not liberate any material which inhibited the growth of its parental white mutant.

The lesion in cell-wall synthesis has not been determined. It may reflect inhibition of mucopeptide synthesis because penicillin, which inhibits cross-linking (Wise \& Park, 1965), prevented the reversion of the $c w d$ variant to white type.

\section{REFERENCES}

LANDMAN, O. E. (I968). Protoplasts, spheroplasts and L-forms viewed as a genetic system, pp. 3I9-332. In Microbial Protoplasts, Spheroplasts and L-forms. Edited by L. B. Guze. Baltimore: Williams and Wilkins.

WiSE, E. M. \& PARK, J. T. (I965). Penicillin: its basic site of action as an inhibitor of a peptide cross linking reaction in cell wall mucopeptide synthesis. Proceedings National Academy of Sciences of the United States of America 54, 75-8I. 